TITLE:

\title{
Effect of pre-compressive strain on work-hardening behavior upon two-step loading in a magnesium alloy sheet
}

\section{$\operatorname{AUTHOR}(\mathrm{S}):$}

Hama, Takayuki; Tanaka, Yuhki; Uratani, Masato; Tanaka, Tsutomu; Fujimoto, Hitoshi; Takuda, Hirohiko

\section{CITATION:}

Hama, Takayuki ...[et al]. Effect of pre-compressive strain on work-hardening behavior upon two-step loading in a magnesium alloy sheet. Proceedings of International Conference on Material Science and Engineering 2016 2015, 639: 347-352

\section{ISSUE DATE:}

2015

URL:

http://hdl.handle.net/2433/218300

\section{RIGHT:}

This is not the published version. Please cite only the published version.; この論文は出版社版でありません。引用の際には出版社版を ご確認ご利用ください。 


\title{
Effect of Pre-Compressive Strain on Work-Hardening Behavior upon Two-Step Loading in a Magnesium Alloy Sheet
}

\author{
Takayuki Hama ${ }^{1, a}$, Yuhki Tanaka, ${ }^{1, b}$, Masato Uratani ${ }^{1, c}$, Tsutomu Tanaka $^{2, d}$, \\ Hitoshi Fujimoto $^{1, \mathrm{e}}$ and Hirohiko Takuda ${ }^{1, \mathrm{f}}$ \\ ${ }^{1}$ Graduate school of Energy Science, Kyoto University, Yoshida-honmachi, Sakyo-ku, Kyoto \\ 606-8501, Japan \\ ${ }^{2}$ Technology Research Institute of Osaka Prefecture, 7-1, Ayumino-2, Izumi, Osaka 597-1157, \\ Japan \\ ahama@energy.kyoto-u.ac.jp, byuhki.tanaka.marimo@gmail.com, \\ curatani.masato.28m@st.kyoto-u.ac.jp, ${ }^{d}$ t tanaka@tri-osaka.jp, \\ eh-fujimoto@energy.kyoto-u.ac.jp, ${ }^{\mathrm{f}}$ takuda@energy.kyoto-u.ac.jp
}

Keywords: Magnesium, Sheet Metal, Cross Effect

\begin{abstract}
In the present study, deformation behavior upon two-step loading in a rolled AZ31 Mg alloy sheet was investigated. The experimental procedure was as follows: (1) a sheet was subjected to in-plane compression, (2) small samples were cut from the compressed sheet along various directions, and (3) uniaxial tension was imparted to small samples. The angle between the first and second loading directions was set to either $0,30,60$, or $90^{\circ}$. During the second loading, a strong in-plane anisotropy occurred in the stress-strain curve: a sigmoidal curve occurred during the second loading for the angles of 0 and $30^{\circ}$, while it did not arise for the angles of 60 and $90^{\circ}$. From microstructural observations, it was presumed that the aforementioned results could be explained in terms of the activity of detwinning.
\end{abstract}

\section{Introduction}

Because of the increasing demand for use of lightweight materials in various industries including automobile and electrical devices, Magnesium (hereafter Mg) alloys are drawing a lot of attention [1]. Applications of $\mathrm{Mg}$ alloys can now be found in various components, such as the housing of laptop computers and cellular phones, and automobile components. On the other hand, the number of applications of $\mathrm{Mg}$ alloy sheets to structural components is still small. One of the reasons is that at room temperature rolled Mg alloy sheets show strong anisotropic deformation behavior. For instance, the work-hardening behavior is notably different between tension and compression [2] and depending on a biaxial stress state [3]. The stress-strain curve upon unloading is also different between tension and compression [4]. Moreover, the formability of the sheets at room temperature is much worse than the conventional metal sheets [5]. The above characteristic deformation behavior occurs because a strong basal texture is generally developed in rolled $\mathrm{Mg}$ alloy sheets owing to their hexagonal close-packed (hcp) structure and the activities of twinning and detwinning play an important role in the deformation behavior. The deformation behavior of $\mathrm{Mg}$ alloy sheets has been extensively investigated by researchers both experimentally [6] and numerically [7].

During sheet metal forming, the sheet is often subjected to complicated loading paths such as reverse loading and multiple-step loading where the loading direction is different among the steps. Recently the deformation behavior under cyclic loading including reverse loading has been studied widely in Mg alloy sheets [8] and the effect of twinning and detwinning activities on the work-hardening behavior has been investigated [9]. On the other hand, the deformation behavior under multiple-step loading has been studied scarcely in Mg alloy sheets [10]. It is expected that the work-hardening behavior would also be different notably depending the angle among the loading steps, but it is not understood yet. 
The present study aims at investigating the deformation behavior in a rolled AZ31B Mg alloy sheet under two-step loading where compression and tension are imparted respectively in the first and second loadings. The deformation mechanism is examined focusing on the effect of twinning and detwinning activities.

\section{Experimental Procedure}

A commercially rolled AZ31B Mg sheet (Mg-3\%Al, 1\%Zn, Osaka Fuji Corporation) with $1.0 \mathrm{~mm}$ thickness was used. The sample was annealed for 1.5 hours at $350{ }^{\circ} \mathrm{C}$ before the experiment was conducted. The mechanical properties of the annealed sample are summarized in Table 1.

Table 1: Mechanical properties of a rolled Mg alloy sheet used in the present study.

\begin{tabular}{cccccc}
\hline $\begin{array}{c}E \\
{[\mathrm{GPa}]}\end{array}$ & $\begin{array}{c}\sigma_{\mathrm{T}} \\
{[\mathrm{MPa}]}\end{array}$ & $\begin{array}{c}\sigma_{0.2} \\
{[\mathrm{MPa}]}\end{array}$ & $r_{10 \%}$ & $\begin{array}{c}F \\
{[\mathrm{MPa}]}\end{array}$ & $n$ \\
\hline 43 & 271 & 185 & 1.6 & 451 & 0.18 \\
\hline
\end{tabular}

*The logarithmic strain-true stress curve was approximated using the equation $\sigma=F \varepsilon^{n}$.

Two-step loading tests were conducted as follows. In the first loading, in-plane compression was imparted to a large sample along the rolling direction (hereafter RD). Small samples were then cut using wire electric discharge machining from the compressed large sample along various angles. Thereafter, in-plane tension was applied to the small samples in the second loading. The schematic diagrams of the experiment and the geometries of the large and small samples are shown in Figs. 1 and 2, respectively. The detailed experimental procedures are described in the following.

During the first loading, the sample was compressed to strains of approximately $-3 \%$ or $-6 \%$. In order to eliminate occurrence of buckling during compression, comb-shaped tools were used to give compressive forces in the thickness direction of the sample [11]. The schematic diagrams of the experimental setup and the comb-shape tools are shown in Figs. 3 and 4, respectively. The compressive force in the thickness direction was given by a hydraulic pump and was set to approximately $26 \mathrm{kN}$, which was equivalent to approximately $0.83 \%$ of the $0.2 \%$ proof stress of the sample. Mineral hydraulic oil with a kinematic viscosity of $32 \mathrm{cSt}$ at $40{ }^{\circ} \mathrm{C}$ was used as lubricant to reduce the friction between the comb-shaped tools and the sample.

After the first loading, small samples were machined from the pre-compressed sample along four different angles from the RD, $\theta=0,30,60$, and $90^{\circ}$. The small sample was then subjected to uniaxial tension to a strain of approximately $10 \%$ in the second loading.

In both first and second loadings, the tests were performed at an initial strain rate of $6.67 \times 10^{-4} / \mathrm{s}^{-1}$ at room temperature. A strain gauge (Kyowa Electronic Instruments, KFEM series) was used to measure strains. The experimental data were recorded approximately every $10 \mathrm{~ms}$ during the tests.
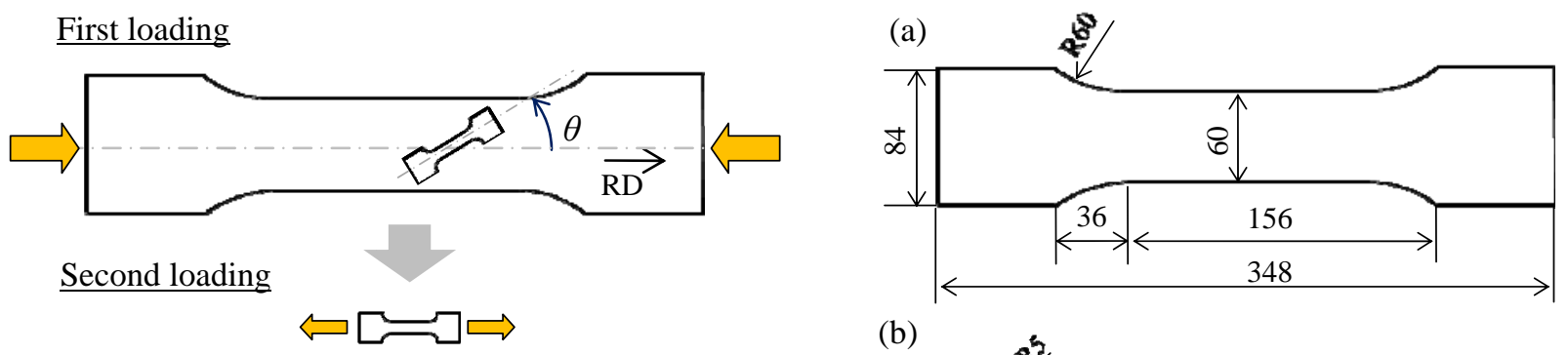

$\theta=0,30,60$, and $90^{\circ}$

(b)

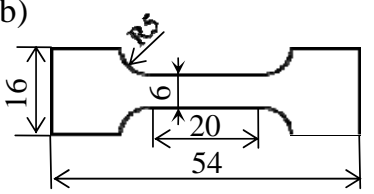

Figure 1: Schematic diagram of two-step loading test

Figure 2: Geometries of (a) large and (b) small samples in mm 


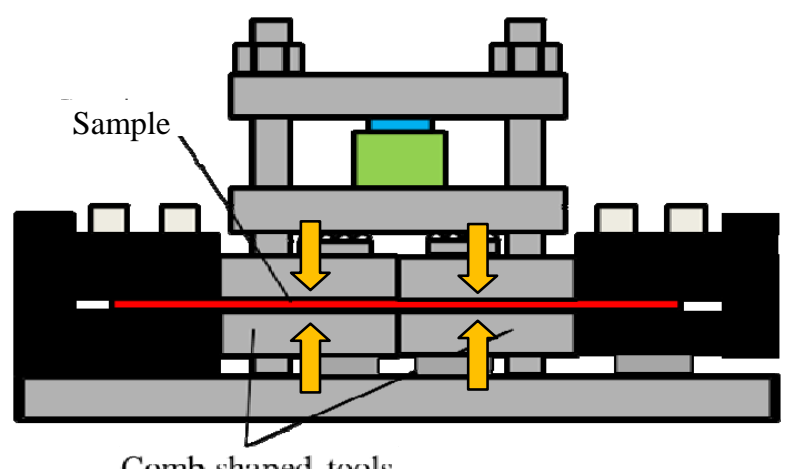

Comb-shaped tools

Figure 3: Schematic diagram of experimental setup

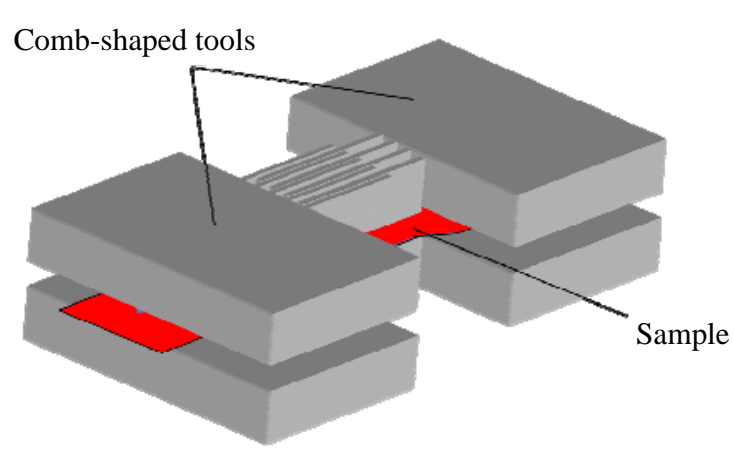

Figure 4: Schematic diagram of comb-shaped tools

After the two-step loading test, microstructures of the deformed samples were observed on the planes perpendicular to the RD using electron backscatter diffraction (EBSD) or an optical microscope. The twin area ratio, $R_{t w i n}$, was used to investigate the activity of twinning and it is given in the form [12]

$$
R_{t w i n}=\frac{S_{t w i n}}{S} \times 100, \quad(\%)
$$

where $S_{t w i n}$ is the area of all presenting twins and $S$ is the whole area of the microstructures observed. The twin area ratio was estimated by image analysis [12] using the free available software Image J.

\section{Results and Discussion}

Experimental Results. The stress-strain curves obtained from the second loading are depicted in Fig. 5. The stress-strain curves show a notable difference depending on the angle $\theta$. The yield stress increases with the increase in the angle $\theta$. A sigmoidal shape is exhibited for $\theta=0$ and $30^{\circ}$, while it hardly occurs for $\theta=60$ and $90^{\circ}$. These qualitative characteristics are independent of the amount of pre-strain, but the plateau regions observed in the sigmoidal shape become large as the pre-strain increases. The above results describe that the compressive pre-strain yields the strong in-plane anisotropy.

Fig. 6 presents the $r$-values measured after the second loading. For reference, the results of the original sample, i.e. the sample without pre-strain, are also displayed. The $r$-value is different depending on the angle $\theta$ and the tendency in the change is almost independnet of the samples. On the other hand, the $r$-values tend to become small as the pre-strain increases. The difference in $r$-value is
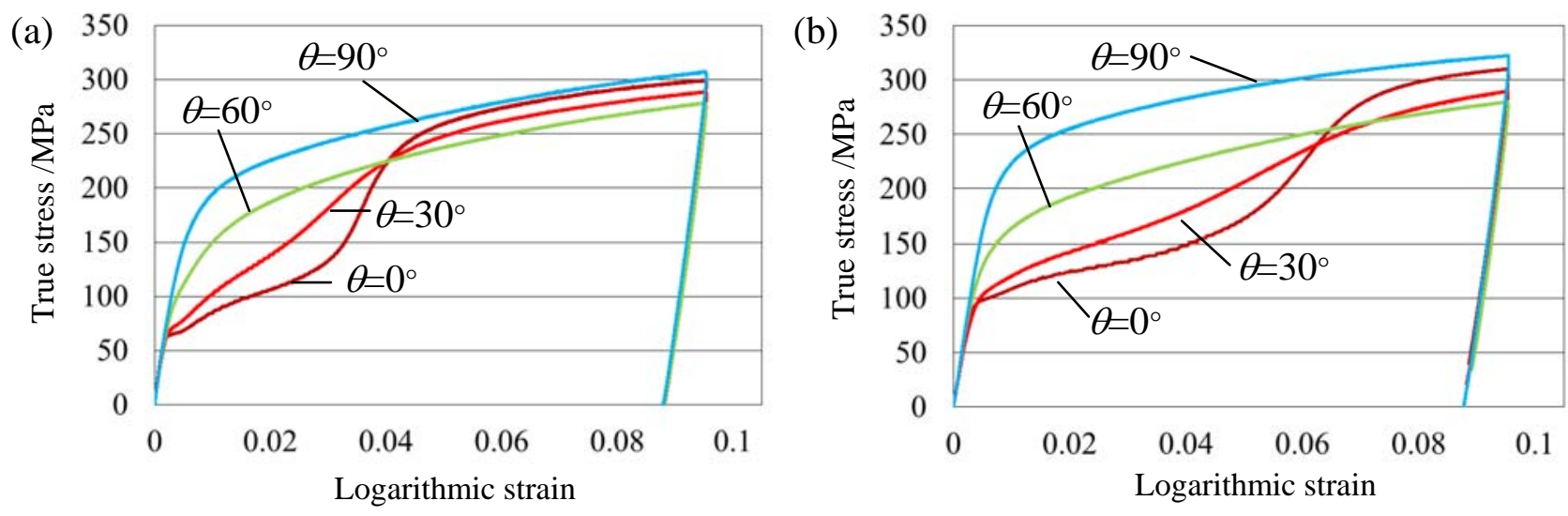

Figure 5: Stress-strain curves upon second loading with pre-strains of (a) $-3 \%$ and (b) -6 \% 
noticeable between the samples without pre-strain and with a pre-strain of $-3 \%$, whereas it is less pronounced between the samples with pre-strains of $-3 \%$ and $-6 \%$.

Discussion. It is established that rolled $\mathrm{Mg}$ alloy sheets exhibit a monotonic increasing tendency in the stress-strain curve under monotonic tension, whereas it depicts a sigmoidal stress-strain curve under compression followed by tension [2], which corresponds to the case of $\theta=0^{\circ}$ in the present study. The mechanism that induces the difference in the stress-strain curves between monotonic tension and compression followed by tension can be explained as follows [13]. The deformation under tension following compression is primarily governed by the activities of detwinning and nonbasal slip in the initial and latter stages, respectively; thus, the change of active deformation mode eventually yields the sigmoidal curve. On the other hand, the deformation under monotonic tension was primarily governed by the activity of prismatic slip throughout the process, yielding the monotonic increasing tendency. This result describes that the difference in the stress-strain curves can be explained in terms of the activity of detwinning.

Because similar differences in stress-strain curves as those mentioned above are observed depending on the angle in the present results, the observed results are examined focusing on the activity of detwinning. In the following, the results of the samples with a pre-strain of $-6 \%$ are used. Fig. 7 shows the (0001) pole figures measured using EBSD. It should be noted that most of twinning

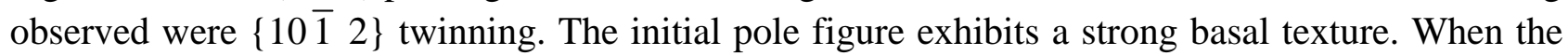
compressive strain was imparted in the first loading, strong peaks occurred in the RD, showing that twinning was activated [2]. After the second loading, the peaks in the RD disappeared in case of $\theta=$ $0^{\circ}$, exhibiting that detwinning was activated. Conversely, the peaks remained in case of $\theta=90^{\circ}$. Clearly, the activity of detwinning would be larger for the sample with $\theta=0^{\circ}$ than $\theta=90^{\circ}$.

To investigate the activity of detwinning more in detail, twin area ratios were measured using an optical microscope. Fig. 8 shows the twin area ratios and examples of the microstructures. The twin

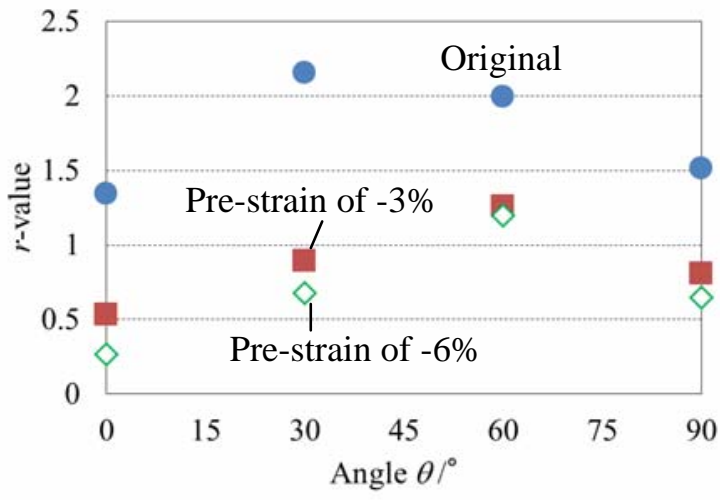

Figure 6: Relationship between angle $\theta$ and $r$-value

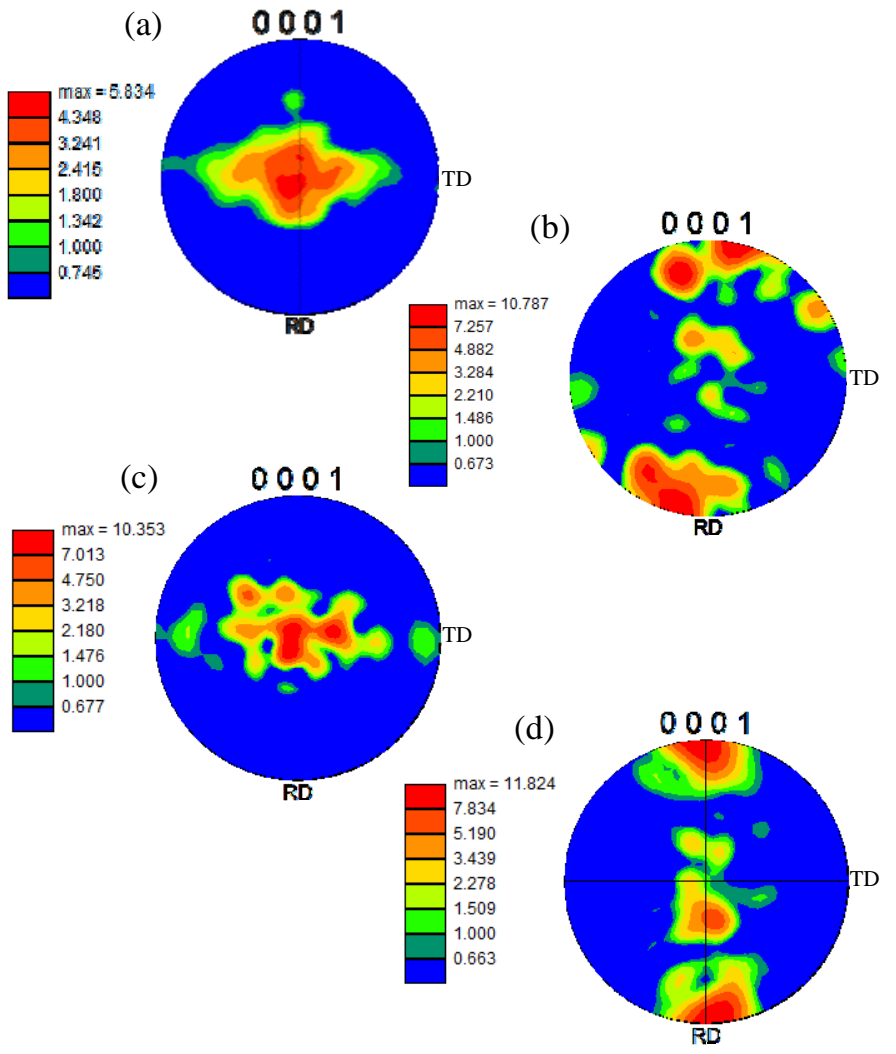

Figure 7: (0001) pole figures. (a) Original, (b) after first loading, (c) after second loading with $\theta=0^{\circ}$, and (d) after second loading with $\theta=90^{\circ}$. TD denotes transverse direction 


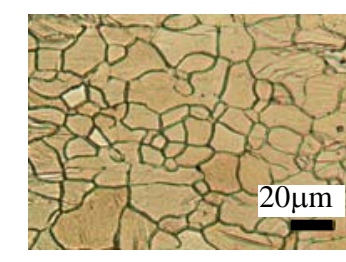

Initial microstructure
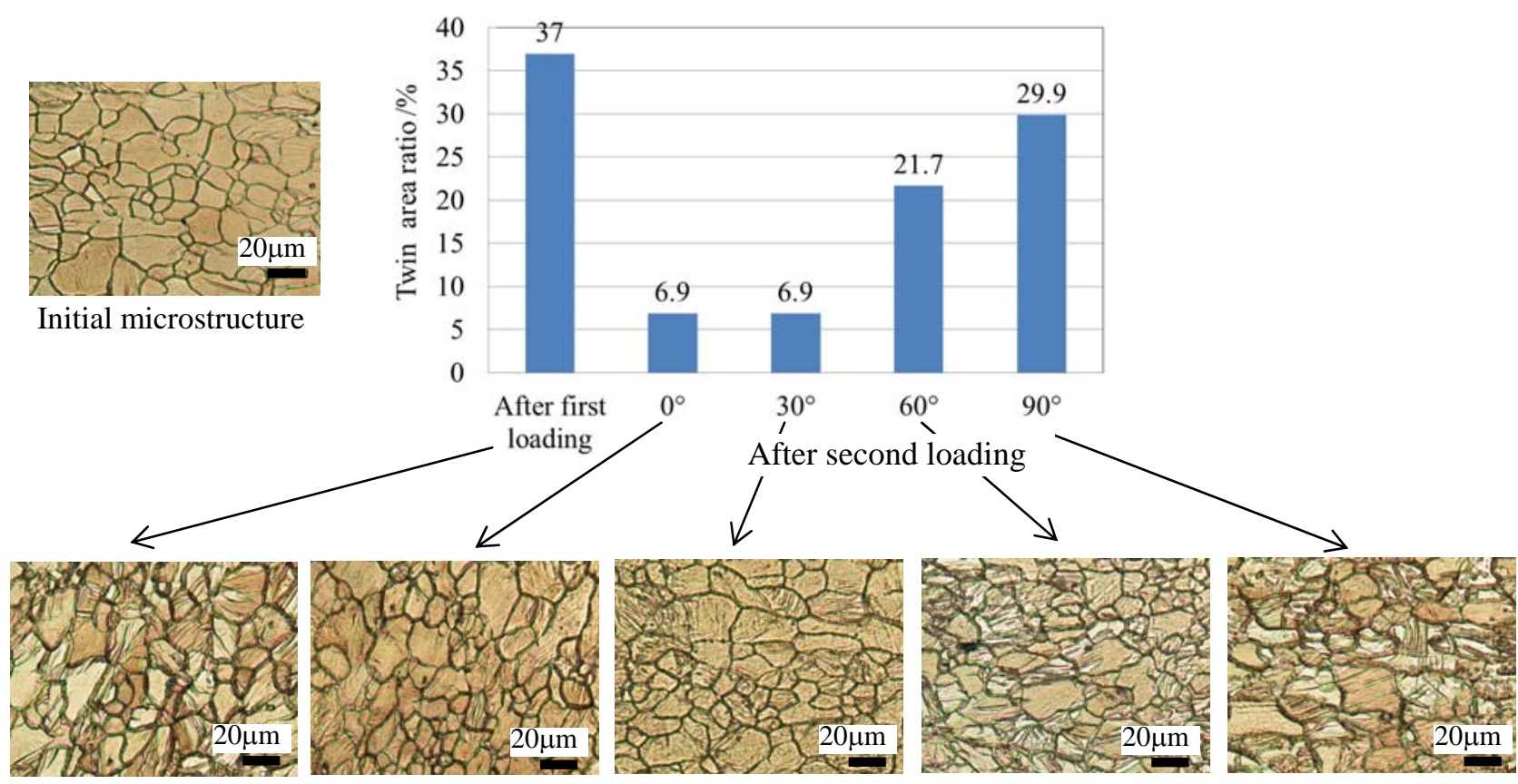

Figure 8: Evolution of twin area ratio

area ratio after the first loading was approximately 37.0 \%. The detwinning activity during the second loading can be estimated from the change in the twin area ratio from this value. In case of $\theta=0^{\circ}$, the ratios after the second loading was approximately $6.9 \%$, indicating that the twin area ratio decreased because of the detwinning activity was approximately $30.1 \%$. The amount of decrease in twin area ratio during the second loading became small as the angle became large, and that in case of $\theta=90^{\circ}$ was approximately $7.1 \%$. This result displays that detwinning became less active as the angle became large, consistent with the tendency observed in the (0001) pole figures. The aforementioned microstructure observations indicate that the sigmoidal shape occurred for $\theta=0$ and $30^{\circ}$ because of the large activity of detwinning, whereas it did not occur for $\theta=60$ and $90^{\circ}$ because the activity of detwinning was very small.

Similarly, the mechanism that the $r$-values decrease as the pre-strain increases can also be explained from the detwinning activity. It is understood that in rolled $\mathrm{Mg}$ alloy sheets shear strain induced by $\{10 \overline{1} 2\}$ twinning affects notably the thickness strain owing to the basal texture. Recently, Steglich et al. [14] reported that an $r$-value for a rolled Mg alloy sheet was much smaller under compression than under tension, exhibiting that twinning affected the $r$-value notably. It is presumed that similar discussion is applicable to detwinning: thickness strain increases because of the detwinning activity and as a result the $r$-value decreases upon tension following compression. The r-values for the sample with pre-strain of $-6 \%$ was smaller than those for the sample with pre-strain of $-3 \%$ would be because the detwinning activity was larger in the sample with pre-strain of $-6 \%$ than that with pre-strain of $-3 \%$ owing to larger amount of twinning activity during the first loading.

It is needless to say that factors other than twinning and detwinning, such as slip activity and texture, should also affect in the deformation upon two-step loading. For instance, the yield stress during the second loading is notably different depending on the angles as shown in Fig. 5. This fact cannot be explained solely from detwinning but the effect of slip activity should be taken into consideration. Moreover, not only detwinning but also other factors including the initial anisotropy and texture should affect the $r$-values after the second loading. Further detailed analyses on other factors are to be conducted both experimentally and numerically in our future work. Moreover, it is established that the activity of twinning and detwinning would become small as the temperature increases: thus, the results should be different depending on the temperature. Because the experiments were conducted only at room temperature in the present study, the effect of temperature on the work-hardening behavior during two-stage loading should be investigated separately. 


\section{Conclusion}

Deformation behavior upon two-step loading in a rolled AZ31 magnesium alloy sheet was investigated at room temperature. Uniaxial compression was imparted in the first loading, while the compressed sample was subjected to uniaxial tension along various directions in the second loading. A sigmoidal curve occurred during the second loading when the angle between the first and second loading directions was small, while it did not arise when the angle was large. This result exhibited that the stress-strain curve presented a strong anisotropy. It was also found that $r$-value became small as the compressive strain became large. Microstructural observations depicted that the aforementioned results could be explained in terms of the detwinning activity during the second loading.

\section{References}

[1] B.L. Mordike, T. Ebert, Magnesium properties - applications- ${ }^{-}$potential. Mater. Sci. Eng. A, 302 (2001), 37-45.

[2] X.Y. Lou, M. Li, R.K. Boger, S.R. Agnew, R.H. Wagoner, Hardening evolution of AZ31B Mg sheet, Int. J. Plast. 23(2007) 44-86.

[3] M.O. Andar, T.Kuwabara, D.Steglich, Material modeling of AZ31 Mg sheet considering variation of $r$-values and asymmetry of the yield locus, Mater. Sci. Eng. A, 549(2012), 82-92.

[4] T. Hama, N. Kitamura, H. Takuda, Effect of twinning and detwinning on inelastic behavior during unloading in a magnesium alloy sheet, Mater. Sci. Eng. A, 583 (2013), 232-241.

[5] X. Huang, K. Suzuki, Y. Chino, M. Mabuchi, Influence of initial texture on cold deep drawability of Mg-3Al-1Zn alloy sheets, Mater. Sci. Eng. A., 565 (2013), 359-372.

[6] J. Koike, Enhanced deformation mechanisms by anisotropic plasticity in polycrystalline $\mathrm{Mg}$ alloys at room temperature, Metall. Mater. Trans. A, 36 (2005), 1689-1696.

[7] T. Hama, H. Takuda, Crystal-Plasticity Finite-Element Analysis of Inelastic Behavior During Unloading in a Magnesium Alloy Sheet, Int. J. Plast., 27(2011) 1072-1092.

[8] L. Wu, S.R. Agnew, Y. Ren, D.W. Brown, B. Clausen, G.M. Stoica, H.R. Wenk, P.K. Liaw, The effects of texture and extension twinning on the low-cycle fatigue behavior of a rolled magnesium alloy, AZ31B, Mater. Sci. Eng. A, 527 (2010), 7057-7067.

[9] T. Hama, T. Mayama, H. Takuda, Deformation behavior of a magnesium alloy sheet with random crystallographic orientations, Key Eng. Mater., 611-612 (2014), 27-32.

[10] S.H. Park, S-G. Hong, C.S. Lee, In-plane anisotropic deformation behavior of rolled Mg-3Al-1Zn alloy by initial \{10-12\} twins, Mater. Sic. Eng. A, 570 (2013), 149-163.

[11] T. Kuwabara, Y. Kumano, J. Ziegelheim, I. Kurosaki, Tension-compression asymmetry of phosphor bronze for electronic parts and its effect on bending behavior, Int. J. Plasticity, 25 (2009), 1759-1776.

[12] Y. Chino, K. Kimura, M. Mabuchi, Twinning behavior and deformation mechanisms of extruded AZ31 Mg alloy, Mater. Sci. Eng. A, 486 (2008), 481-488.

[13] T. Hama, H. Takuda, Work-hardening behavior upon reverse loading in a rolled AZ31 magnesium alloy sheet, Key, Eng. Mater., 622-623 (2014), 603-608.

[14] D. Steglich, X. Tian, J. Bohlen, T. Kuwabara, Mechanical testing of thin sheet magnesium alloys in biaxial tension and uniaxial compression, Exp. Mech., 54 (2014), 1247-1258. 